\title{
MONITORING POPULACIJE ZLATOKRAJA (Euproctis chrysorrhoea L.) NA PODRUČJU SREDIŠNJE BOSNE
}

\section{MONITORING OF POPULATIONS OF BROWNTAIL MOTH (Euproctis chrysorrhoea L.) IN THE CENTRAL BOSNIA}

\author{
Osman MUJEZINOVIĆ ${ }^{1}$, Mevaida MEŠAN² ${ }^{2}$ Mirza DAUTBAŠIĆ* ${ }^{*}$ Kenan ZAHIROVIĆ ${ }^{3}$
}

\begin{abstract}
Sažetak
Za potrebe ovog rada utvrđena je štetnost zlatokraja (E. chrysorrhoea L.) na području ŠPD-a "Srednjobosanske" šume, odnosno na području Šumarija Novi Travnik, Travnik i Kreševo. Proveden je monitoring populacije zlatokraja primjenom represivnih mjera koje su obuhvatile primjenu klopki i feromona. Za potrebe ovog istraživanja korištene su klopke WitaTrap Delta PQ i feromoni Chrysowit. Monitoring populacije zlatokraja je analiziran tijekom 2014. i 2015. godine sa po dva mjerenja. Za Šumariju Novi Travnik utvrđeno je da je broj ulovljenih jedinki zlatokraja u 2015. godini znatno manji u odnosu na 2014 godinu. Za Šumariju Travnik i Kreševo je broj ulovljenih jedinki zlatokraja u 2015 godini znatno veći u odnosu na 2014 godinu. Prosječan broj ulovljenih jedinki na lokalitetima istraživanja kretao se od 1,68 do 22,39 jedinki.
\end{abstract}

KLJUČNE RIJEČI: srednja Bosna, hrast, Lymantriidae, WitaTrap Delta PQ, Chrysowit.

\section{UVOD}

\section{INTRODUCTION}

E. chrysorrhoea L. je štetnik koji uzrokuje teška oštećenja šumskog drveća, posebno hrasta, u centralnoj, srednjoj i južnoj Europi, Sjevernoj Africi, Srednjoj Aziji, Sjevernoj Americi i nekim dijelovima Engleske (Alford, 1995). Štetnik je također evidentiran u sjeverozapadnom području Irana (Abaei, 2000). Prirodna rasprostranjenost E. chrysorrhoea L. proteže se preko cijele Europe, uključujući Britaniju, južnu Norvešku i Švedsku i sva umjerena područja Sjeverne
Afrike i Azije (Schaefer, 1986; Schaefer, 1989). Ne pojavljuje u Japanu (Inoue, 1957), Koreji (Nam et al., 1981), a navodno se pojavljuje i u Kini (Chao, 1978).

Europska je vrsta slučajno indroducirana u Sjevernu Ameriku 1897. godine, nakon čega je postao ozbiljan štetnik šumskog drveća i grmlja koja zahtijeva kontrolu, međutim, danas se ta vrsta ne može smatrati invazivnom (Schaefer, 1974; Elkinton et al., 2008). Također je od javnog zdravstvenog interesa zbog dermatitisa koji izaziva kod ljudi uzrokovan dodirom s dlakama iz gusjenice (Sterling et al., 1988;

\footnotetext{
* prof. dr. sc. Mirza Dautbašić, Šumarski fakultet Univerziteta u Sarajevu, Katedra za zaštitu šuma, urbanog zelenila i lovnog gospodarenja, Zagrebačka 20, 71000 Sarajevo, Bosna i Hercegovina, e-mail: mirzad@bih.net.ba

1 prof. dr. sc. Osman Mujezinović, Šumarski fakultet Univerziteta u Sarajevu, Katedra za zaštitu šuma, urbanog zelenila i lovnog gospodarenja, Zagrebačka 20, 71000 Sarajevo, Bosna i Hercegovina, e-mail: osmansfs@yahoo.com

2 Mr. sc. šum. Mevaida Mešan, Šumskoprivredno društvo "Srednjobosanske šume", 770. slavne brdske brigade bb., 70220 Donji Vakuf, Bosna i Hercegovina, e-mail: mesanmevaida@gmail.com

${ }^{3}$ Kenan Zahirović, mag. ing. silv., JP Šumsko-privredno društvo Zeničko-dobojskog kantona d.o.o Zavidovići, Alije Izetbegovića 25, 72220 Zavidovići, Bosna i Hercegovina, e-mail: zahirovic_kenan@yahoo.com
} 

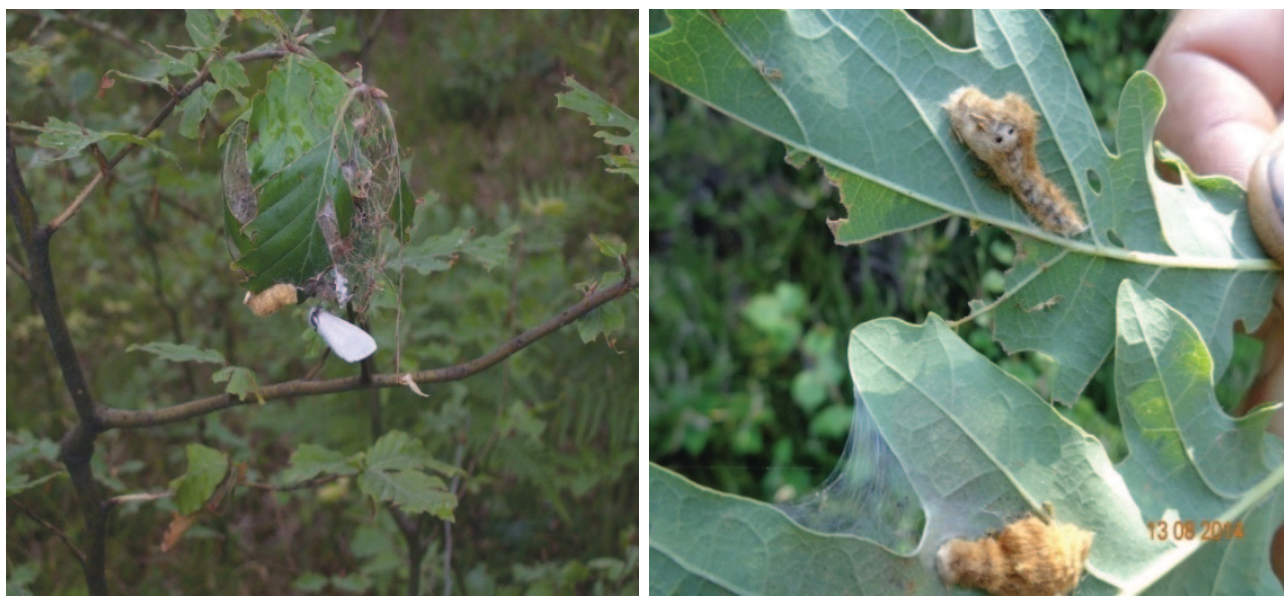

Slika 1 i 2. Imago i jajno leglo štetnika $E$. chrysorrhoea L.

Picture 1 and 2. Adult and egg masses of pests $E$. chrysorrhoea $\mathrm{L}$.
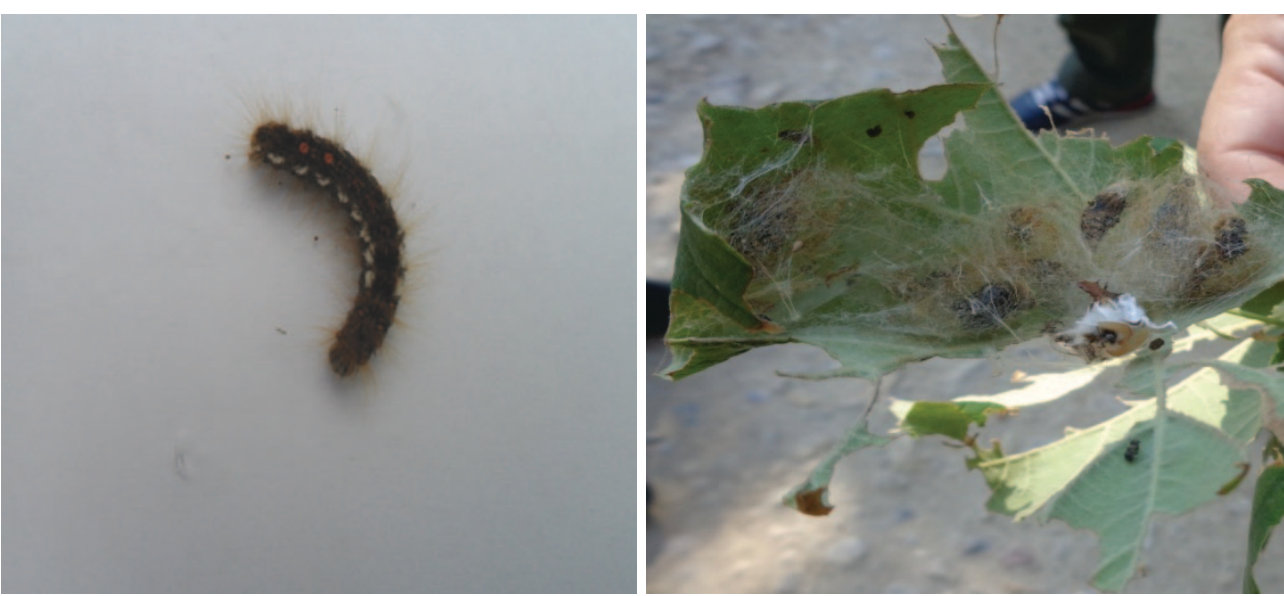

Slika 3 i 4 . Gusjenica i kukuljica štetnika $E$. chrysorrhoea L.

Picture 3 and 4. Larvae and puppet of pests $E$. chrysorrhoea L.

Eroglu, 1992). Ovaj štetnik još uvijek uzrokuje ozbiljne periodične štete, unatoč neprekidnom radu kako bi se mogao kontrolirati u Europi (Lipa et al., 1980; Eroglu, 1992; Sliwa, 1993; Lipa, 1996).

U Hrvatskoj se smatra za štetnika nizinskih krajeva, posebice u Posavini i Podravini. Ovo je dobro poznati defolijator hrasta lužnjaka, posebno njegovih kasnih formi u nizijskim šumama zapadnog dijela Hrvatske (Mikloš, 1988). U Bosni i Hercegovini evidentiran je u prenamnoženju 2014. godine u Srednjoj Bosni na području općina Novi Travnik, Travnik i Kreševo.

E. chrysorrhoea L. je polifagni štetnik koji se hrani lišćem velikog broja vrsta listopadnog drveća, grmlja, a štete pričinjava i u voćnjacima. Nikad ne napada četinjače (Serafimovski et al., 1976). Prema Marques et al. (2014) evidentirano je hranjenje vrste na 26 rodova iz 13 različitih familija od hrasta do divlje ruže među kojima su: Acer campestre, Fagus sp., Amelancchier ovalis, Betula sp., Carpinus betulus, Cornus sanguinea, Corylus avellana, Crataegus sp., Fraxinus sp., Malus domestica, Populus sp., Quercus sp., Rosa sp., Rubus fruticosus, Salix sp. Ženka je bijele boje, opseg krila 3,2-4 $\mathrm{cm}$, njezin trbuh je od sedmog segmenta i na vrhu prekriven zlatno-smeđim dlakama. Ticala su kratka i zupčasta. Mužjaci su bijeli, ali na prednjim krilima ponekad imaju nekoliko malih crnih točaka. Opseg njihovih krila 2,6-3,2 $\mathrm{cm}$, trbuh kod mužjaka je uži i od trećeg segmenta prekriven je crveno-smeđim dlakama. Ticala su perasta (Serafimovski et al., 1976) (slika 1).

Oplođene ženke polažu okrugla sivo-smeđa jaja u jajna legla. Svaka ženka položi oko 200-400 jaja. Kuglasta jaja duga su oko $0,84 \mathrm{~mm}$, a široka $0,47 \mathrm{~mm}$. Jaja potamne nakon početka embrionalnog razvoja (Candan, 2007). Položena jaja ženka pokriva žutim dlačicama koje skida sa trbuha zajedno sa svojim žljezdanim sekretima. Prekrivanje jaja pruža dobru zaštitu od predatora, lošeg vremena i pretjerane insolacije (Arevalo-Durup, 1991). Jajna legla imaju okrugao, a rjeđe nepravilan oblik (Serafimovski et al., 1976). U slučaju veće brojnosti populacije jajna legla se mogu naći i na kori drveća, ali najčešće na lišću ne birajući njegovu stranu, kao i u vršnim djelovima krošnje stabla pa čak i na starim gnijezdima (Cleve, 1972) (slika 2).

Gusjenica je crnosive boje sa dvije rđastocrvene linije s leđne strane, a sa svake strane ima po jednu bijelu liniju koja je sastavljena od kosih crtica. Dužina gusjenice je 30-40 mm (Serafimovski et al., 1976). Noge kod gusjenice su smeđkasto-crne. Glava je crno-smeđa, sjajna. Trbuh je siv sa žutim dnom. Na kraju tijela (9 i 10 segment) su dvije žlijezde narančasto-crvene boje koje luče otrovni sekret koji se zadr- 
žava na okolnim dlačicama, te one imaju sposobnost žarenja i ako je gusjenica uznemirena ili napadnuta služi joj za pasivnu odbranu (Vasiljev, 1984) (slika 3).

Kukulje se u zapretku smeđe boje, dužina kukuljice je oko $20 \mathrm{~mm}$, a naglo se sužava prema stražnjem kraju (Serafimovski et al., 1976). Kukuljenje gusjenica počinje nakon što prođu kroz šest do osam larvenih stadija razvoja (Frago et al., 2009; Arevalo-Durup, 1991; Vasiljev, 1984) (slika 4).

E. chrysorrhoea L. stvara jednu generaciju godišnje. Vrstu također karakterizira osebujan životni ciklus jer veći dio godine (10 mjeseci) provede u stadiju gusjenice, a prezimljava kao mlada gusjenica, u gregarnim zapredcima (Schaefer, 1986).

Rojenje leptira uvjetovano je vremenskim uvjetima. Roji se tijekom mjeseca srpnja i kolovoza. Izlegu se sa potpuno razvijenim seksualnim organima (Arevalo-Durup, 1991). Jako su fotofilni, što im pomaže pri preseljavanju s jedne na drugu lokaciju (Serafimovski et al., 1976). Prema Frago (2010) u prirodnim uvjetima gusjenice E. chrysorrhoea L. obično se izlegu sredinom ljeta, hrane se gregarno i prolaze kroz dijapauzu kao mlade gusjenice početkom jeseni unutar zapredaka. Nakon nekoliko mjeseci dijapauze, gusjenice nastavljaju hranjenje u rano proljeće, a zatim se kukulje u rano ljeto. Odrasle jedinke ove vrste se ne hrane i kratko žive (5-7 dana) kratkoća života fokusirana je samo na reprodukciju. Nakon 2-3 tjedna koliko traje embrionalni razvoj iz jaja se izlegu male gusjenice (krajem srpnja i početkom kolovoza), na većim nadmorskim visinama embrionalni razvoj može se produžiti za nekoliko dana (Serafimovski et al., 1976).

Pri temperaturi od $20-30^{\circ} \mathrm{C}$ razvoj gusjenice završava se za 30-44 dana. Na temperaturi od $17^{\circ} \mathrm{C}$ razvoj je produžen do 78 dana. Fluktuacije u zavisnosti od relativne vlažnosti su: optimalna vlažnost je u rasponu od 40-75 \% i tada donja relativna vlažnost djeluje manje negativno nego veća (Grichanov et al., 2004). Eklozija gusjenica u nizinskim krajevima nastaje obično krajem lipnja, međutim to se događa i

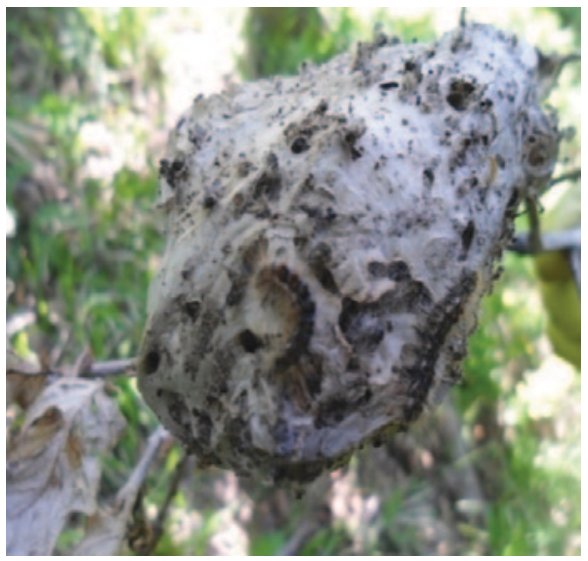

Slika 5.

Zapredak štetnika E. chrysorrhoea L. Picture 5. Coccon of pest E. chrysorrhoea L.

u kolovozu. U mlađim larvenim stadijima gusjenice se razvijaju vrlo sporo i do zime se presvuku dva puta. Do trećeg larvenog stadija (u kome prezimljavaju) grupno skeletiraju lišće, prelazeći s jednog lista na drugi. Krajem rujna već su izgradile zapredke od cijelih ili djelimično skeletiranih listova spojenih i obavijenim bijelim paučinastim omotačem. U zavisnosti od gustoće populacije u ovim zapredcima se može naći od 400-1000 jedinki, svaka u posebno ispredenoj komorici. Zapredak čini više manjih gnijezda na kojima se nalaze otvori kroz koji gusjenice izlaze na hranjenje (Grichanov et al., 2004) (slika 5).

\section{Materijali i metode istraživanja - Materials and Methods of Research}

Istraživanja su se obavila na području Šumarija Novi Travnik, Travnik i Kreševo u okviru ŠPD-a „Srednjobosanske šume" d.o.o. Donji Vakuf. U 2014. godini monitoring populacije zlatokraja obavljao se od 10.7 do 30.7., a u 2015. godini od 9.6 do 24.7., sa po dva mjerenja u razmaku od 10-15 dana. Za potrebe monitoringa populacije zlatokraja na ovome lokalitetu korišten je feromonski pripravak Chrysowit i klopka tipa WitaTrap Delta PQ, koje su postavljane na visinu od 1,4 m. Feromonski pripravak Chrysowit je seksualni feromon, koji „privlači“ mužjake (slika 6 i 7).

Slika 6 i 7. Klopka tipa WitaTrap Delta PO i brojanje ulovljenih jedinki štetnika $E$. chrysorrhoea $\mathrm{L}$. Picture 6 and 7. The trap type of WitaTrap Delta PQ and counting individuals of caught pest $E$. chrysorrhoea L.
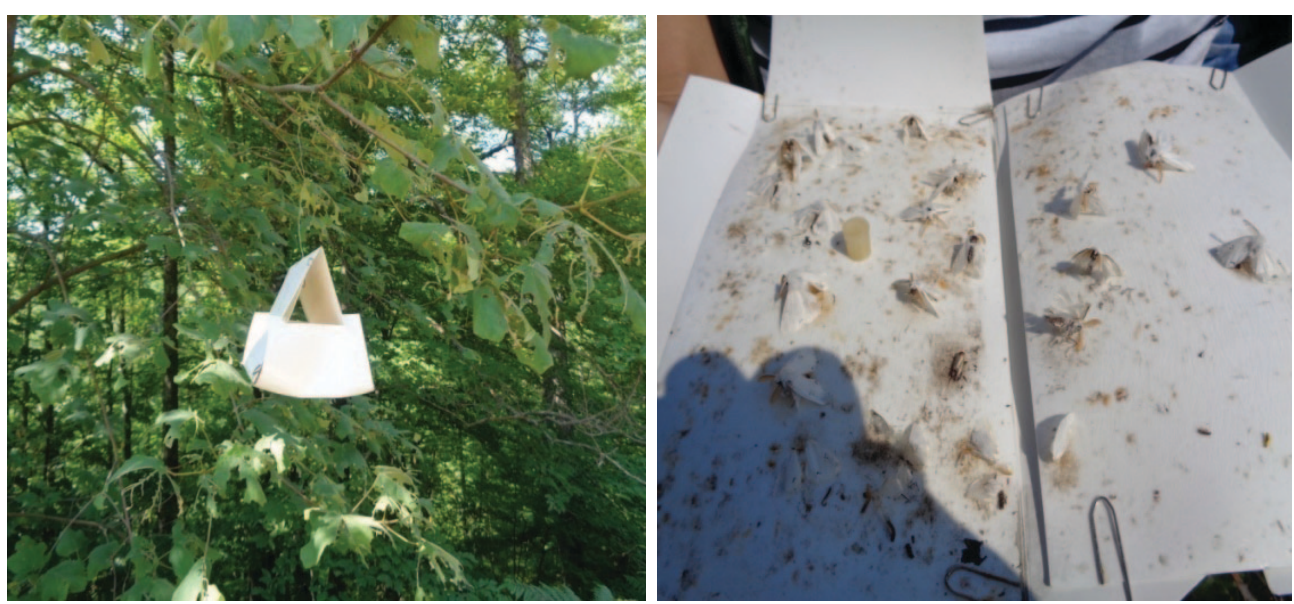
Tablica 1. Lokaliteti na kojima se obavljao monitoring populacije $E$. chrysorrhoea L. u 2014. i 2015. godini

Table 1. The sites where is monitored population of E. chrysorrhoea L. in 2014 and 2015 year

\begin{tabular}{lcc}
$\begin{array}{l}\text { Šumarija/ } \\
\text { Forest Office }\end{array}$ & $\begin{array}{c}\text { Gospodarska jedinica/ } \\
\text { Management Unit }\end{array}$ & $\begin{array}{c}\text { Odjeljenje/ } \\
\text { Department }\end{array}$ \\
\hline Novi Travnik & $105 / 1$ \\
& Vilenica-Risovac & $106 / 1$ \\
& & $106 / 2$ \\
& & 107 \\
Travnik & Goleš-Radalje & 3 \\
& & 9 \\
& & 13 \\
& Vilenica-Risovac & 48 \\
& & 53 \\
Kreševo & & $412 / 1$ \\
& Crna Rijeka-Fojnička & 49 \\
& & 52 \\
& & 53 \\
& & 21 \\
& & 22
\end{tabular}

U tablici 1 prikazani su lokaliteti na kojima se obavljalo postavljanje feromona i feromonskih klopki.

\section{REZULTATI}

RESULTS

Rezultati I i II brojanja za Šumariju N. Travnik prikazani su na grafikonu 1.

U tablici 2 prikazana je deskriptivna statistika za broj ulovljenih jedinki zlatokraja nakon I i II brojanja u 2014. godini na području Šumarije N. Travnik.

U tablici 3 prikazana je deskriptivna statistika za broj ulovljenih jedinki nakon I i II brojanja u 2015. godini na području Šumarije N. Travnik.

Rezultati I i II brojanja za Šumariju Travnik su prikazani na grafikonu 2.

Tablica 2. Deskriptivna statistika za broj ulovljenih jedinki $E$. chrysorrhoea L. nakon I i II brojanja u 2014. godini za područje Šumarije N. Travnik

Table 2. Descriptive statistics for the number of caught individuals of $E$. chrysorrhoea L. after the first and second counting in 2014 for the area of the Forest Office N. Travnik

\begin{tabular}{lrlr}
\multicolumn{2}{c}{ I brojanje / / counting } & \multicolumn{1}{c}{ || brojanje / // counting } \\
Aritmetička sredina / & 6,42 & Aritmetička sredina / & 4,39 \\
Arithmetic mean & & Arithmetic mean & \\
Medijana / Median & 4,00 & Medijana / Median & 2,00 \\
Mod / Mod & 0,00 & Mod / Mod & 0,00 \\
Standardna devijacija / & 8,09 & Standardna devijacija / & 6,34 \\
Standard deviation & & Standard deviation & 40,31 \\
Varijansa / Variance & 65,49 & Varijansa / Variance & 40,00 \\
Minimum & 0,00 & Minimum & 0,00 \\
Maximum & 40,00 & Maximum & 36,00
\end{tabular}

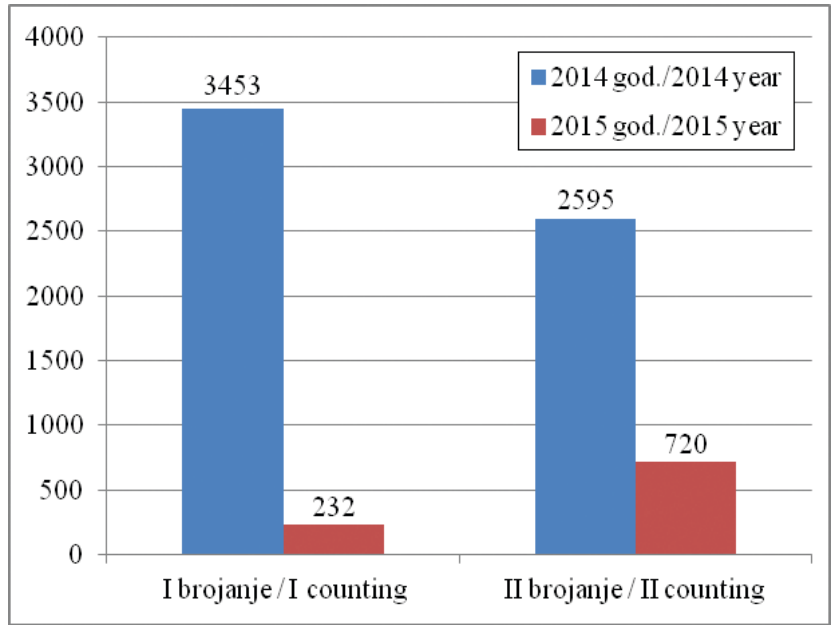

Grafikon 1. Broj ulovljenih jedinki E. chrysorrhoea L. nakon I i ll brojanja u 2014. i 2015. godini za područje Šumarije N. Travnik

Chart 1. The number of caught individuals of $E$. chrysorrhoea $\mathrm{L}$. after the first and second counting in 2014 and 2015 year for the area of the Forest Office N. Travnik

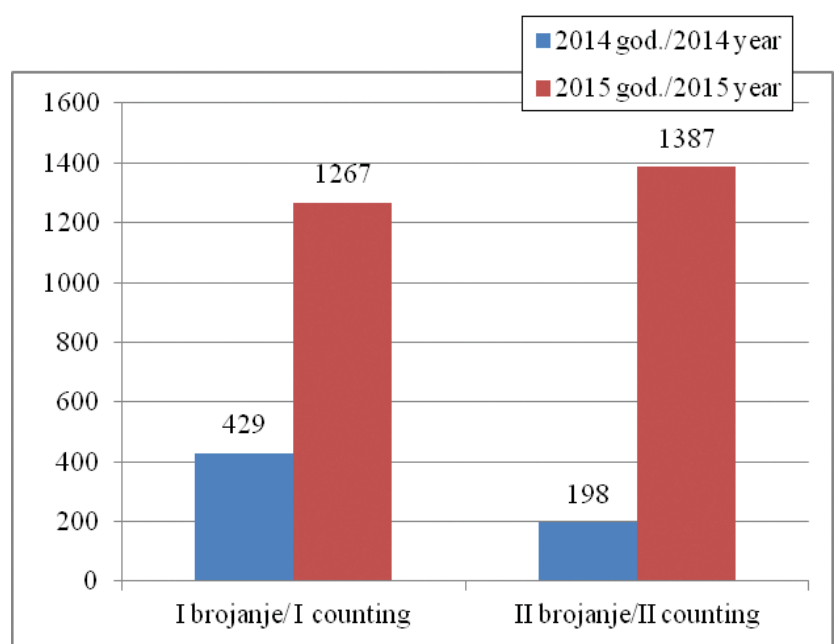

Grafikon 2. Broj ulovljenih jedinki E. chrysorrhoea L. nakon I i II brojanja u 2014. i 2015. godini za područje Šumarije Travnik

Chart 2. The number of caught individuals of $E$. chrysorrhoea $L$. after the first and second counting in 2014 and 2015 year for the area of the Forest Office Travnik

Tablica 3. Deskriptivna statistika za broj ulovljenih jedinki E. chrysorrhoea L. nakon I i II brojanja u 2015. godini za područje Šumarije N. Travnik

Table 3. Descriptive statistics for the number of caught individuals of $E$. chrysorrhoea L. after the first and second counting in 2015 for the area of the Forest Office N. Travnik

\begin{tabular}{lrlr}
\multicolumn{2}{c}{ I brojanje / / counting } & \multicolumn{1}{c}{ || brojanje / // counting } \\
Aritmetička sredina / & \multirow{2}{*}{ Aritmetička sredina / } & 12,00 \\
Arithmetic mean & & Arithmetic mean & 10,00 \\
Medijana / Median & 1,00 & Medijana / Median & 8,00 \\
Mod / Mod & 0,00 & Mod / Mod & 8,06 \\
Standardna devijacija / & 5,56 & Standardna devijacija / & Standard deviation \\
Standard deviation & & Varijansa / Variance & 65,01 \\
Varijansa / Variance & 30,93 & Minimum & 1,00 \\
Minimum & 0,00 & Maximum & 30,00
\end{tabular}


Tablica 4. Deskriptivna statistika za broj ulovljenih jedinki E. chrysorrhoea L. nakon I i II brojanja u 2014. godini za područje Šumarije Travnik Table 4. Descriptive statistics for the number of caught individuals of $E$. chrysorrhoea L. after the first and second counting in 2014 for the area of the Forest Office Travnik

\begin{tabular}{lrlr}
\multicolumn{2}{c}{ I brojanje / / counting } & \multicolumn{2}{c}{ || brojanje / // counting } \\
Aritmetička sredina / & 5,43 & Aritmetička sredina / & 2,50 \\
Arithmetic mean & 3,00 & Arithmetic mean & Medijana / Median \\
Medijana / Median & 1,00 & Mod / Mod & 0,00 \\
Mod / Mod & 6,24 & Standardna devijacija / & 2,27 \\
Standardna devijacija / & Standard deviation & 5,17 \\
Standard deviation & 38,94 & Varijansa / Variance & 0,00 \\
Varijansa / Variance & 0,00 & Minimum & 10,00 \\
Minimum & 27,00 & Maximum &
\end{tabular}

Tablica 5. Deskriptivna statistika za broj ulovljenih jedinki E. chrysorrhoea L. nakon I i Il brojanja u 2015. godini za područje Šumarije Travnik Table 5. Descriptive statistics for the number of caught individuals of $E$. chrysorrhoea L. after the first and second counting in 2015 for the area of the Forest Office Travnik

\begin{tabular}{lrlr}
\multicolumn{2}{c}{ I brojanje/ / counting } & \multicolumn{2}{c}{ || brojanje/ I/ counting } \\
Aritmetička sredina / & 15,08 & Aritmetička sredina / & 16,51 \\
Arithmetic mean & & Arithmetic mean & 16,00 \\
Medijana / Median & 14,00 & Medijana / Median & 0,00 \\
Mod / Mod & 0,00 & Mod / Mod & 0,00 \\
Standardna devijacija / & 12,80 & Standardna devijacija / & 13,40 \\
Standard deviation & Standard deviation & 179,67 \\
Varijansa / Variance & 164,02 & Varijansa / Variance & 0,00 \\
Minimum & 0,00 & Minimum & 44,00
\end{tabular}

U tablici 4 prikazana je deskriptivna statistika za broj ulovljenih jedinki nakon I i II brojanja u 2014. godini na području Šumarije Travnik.

U tablici 5 prikazana je deskriptivna statistika za broj ulovljenih jedinki nakon I i II brojanja u 2015. godini na području Šumarije Travnik.

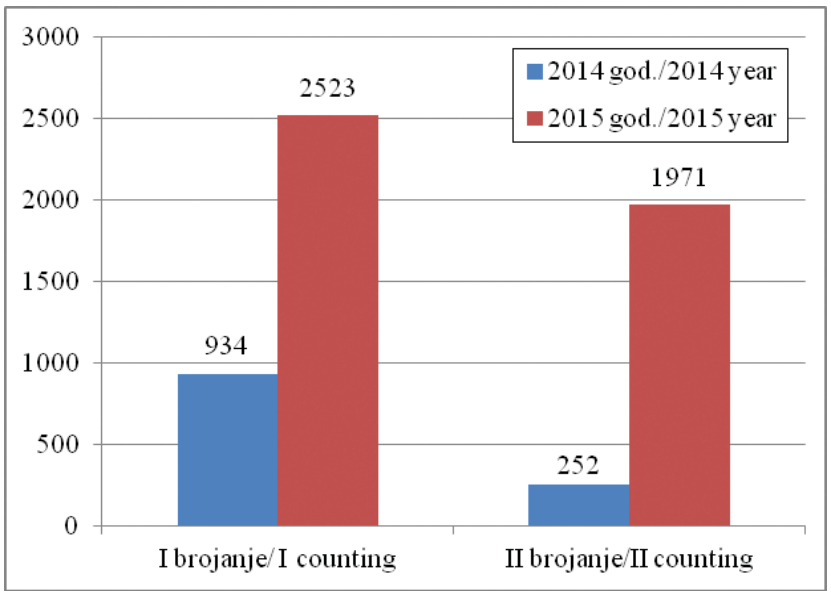

Grafikon 3. Broj ulovljenih jedinki E. chrysorrhoea L. nakon I i Il brojanja u 2014. i 2015. godini za područje Šumarije Kreševo

Chart 3. The number of caught individuals of $E$. chrysorrhoea L. after the first and second counting in 2014 and 2015 year for the area of the Forest Office Kreševo
Tablica 6. Deskriptivna statistika za broj ulovljenih jedinki E. chrysorrhoea L. nakon I i II brojanja u 2014. godini za područje Sumarije Kreševo

Table 6. Descriptive statistics for the number of caught individuals of $E$. chrysorrhoea L. after the first and second counting in 2014 for the area of the Forest Office Kreševo

\begin{tabular}{lrlr}
\multicolumn{1}{c}{ I brojanje/ / counting } & \multicolumn{2}{c}{ || brojanje/ I/ counting } \\
Aritmetička sredina / & 6,22 & Aritmetička sredina / & 1,68 \\
Arithmetic mean & 4,00 & Arithmetic mean & 1,00 \\
Medijana / Median & 3,00 & Mod / Mod & 1,00 \\
Mod / Mod & 5,82 & Standardna devijacija & 2,06 \\
Standardna devijacija / & / Standard deviation & \\
Standard deviation & 33,90 & Varijansa / Variance & 4,24 \\
Varijansa / Variance & 0,00 & Minimum & 0,00 \\
Minimum & 28,00 & Maximum & 13,00
\end{tabular}

Tablica 7. Deskriptivna statistika za broj ulovljenih jedinki $E$. chrysorrhoea L. nakon I i II brojanja u 2015. godini za područje Sumarije Kreševo

Table 7. Descriptive statistics for the number of caught individuals of $E$. chrysorrhoea L. after the first and second counting in 2015 for the area of the Forest Office Kreševo

\begin{tabular}{lrlr}
\multicolumn{2}{c}{ I brojanje/ / counting } & \multicolumn{2}{c}{ || brojanje/ I/ counting } \\
Aritmetička sredina / & 19,11 & Aritmetička sredina / & 22,39 \\
Arithmetic mean & 21,00 & Arithmetic mean & Medijana / Median \\
Medijana / Median & 25,00 \\
Mod / Mod & 26,00 & Mod / Mod & 29,00 \\
Standardna devijacija & 9,58 & Standardna devijacija / & 9,87 \\
/ Standard deviation & & Standard deviation & \\
Varijansa / Variance & 91,90 & Varijansa / Variance & 97,43 \\
Minimum & 0,00 & Minimum & 0,00 \\
Maximum & 38,00 & Maximum & 40,00
\end{tabular}

Rezultati I i II brojanja za Šumariju Kreševo prikazani su na grafikonu 3.

U tablici 6 prikazana je deskriptivna statistika za broj ulovljenih jedinki nakon I i II brojanja u 2014. godini na području Šumarije Kreševo.

U tablici 7 prikazana je deskriptivna statistika za broj ulovljenih jedinki nakon I i II brojanja u 2015. godini na području Šumarije Kreševo.

\section{RASPRAVA DISCUSSION}

Zlatokraj u kompleksu s drugim štetnicima biotičke i abiotičke prirode, može dovesti do odumiranja i degradacije šumskih ekosustava, posebno hrastovih šuma (Stanivuković, 2013.). Monitoring populacije zlatokraja uslijed prenamnoženja vršen je primjenom klopki i feromona (Leonhard et al., 1991.). Za potrebe ovog istraživanja korištene su klopke WitaTrap Delta PQ i feromon Chrysowit. Autori su koristili i druge klopke od kojih je najvažnija Pherocon 1C, Light trap (Leonhard et al., 1991; Lakatos i Tuba, 2011). Prva istraživanja sa seksualnim feromonima kod ovog štetnika proveo je Khrimianet et al. (2008.). Monitoring populacije zlatokraja je analiziran u toku 2014 i 2015 godine sa po dva mjerenja. Za Šumariju N. Travnik utvrđeno je da je broj 
ulovljenih jedinki zlatokraja u 2014. godini veći u I brojanju (3453) u odnosu na II brojanje (2595), a u 2015. godini manji u I brojanju (232) u odnosu na II brojanje (720) (grafikon 1). Prosječan ulov jedinki zlatokraja u 2014. godini po klopci za I brojanje iznosi 6,42 jedinki, dok za II brojanje iznosi 4,39 jedinki (tablica 2), u 2015. godini za I brojanje iznosi 3,86 jedinki, a za II brojanje iznosi 12,0 jedinki (tablica 3).

Za Šumariju Travnik utvrđeno je da je broj ulovljenih jedinki zlatokraja u 2014. godini veći u I brojanju (429) u odnosu na II brojanje (198), a u 2015. godini manji u I brojanju (1267) u odnosu na II brojanje (1387) (grafikon 2). Prosječan ulov jedinki zlatokraja u 2014. godini po klopci za I brojanje iznosi 5,43 jedinki, dok za II brojanje iznosi 2,50 jedinki (tablica 4), u 2015. godini za I brojanje iznosi 15,08 jedinki, a za II brojanje iznosi 16,51 jedinki (tablica 5).

Za Šumariju Kreševo utvrđeno je da je broj ulovljenih jedinki zlatokraja u 2014. godini veći u I brojanju (934) u odnosu na II brojanje (252), a u 2015. godini veći u I brojanju (2523) u odnosu na II brojanje (1971) (grafikon 3). Prosječan ulov jedinki zlatokraja u 2014. godini po klopci za I brojanje iznosi 6,22 jedinki, dok za II brojanje iznosi 1,68 jedinki (tablica 6), u 2015. godini za I brojanje iznosi 19,11 jedinki, a za II brojanje iznosi 22,39 jedinki (tablica 7). Broj ulovljenih jedinki zlatokraja za Šumariju Travnik i Kreševo je znatno veći u odnosu na 2014. godinu, na osnovi čega se vidi da se brojnost ovog štetnika na ovom području povećala, što ukazuje na to da je ovo štetnik s izrazitom polifagnošću s tendencijom postizanja velike gustoće populacije (Elkinton et al., 2006).

\section{ZAKLJUČCI}

\section{CONCLUSIONS}

$\mathrm{Na}$ osnovi provedenih terenskih istraživanja došlo se do sljedećih zaključaka:

- više štetnih čimbenika (abiotske i biotske prirode) utiče na propadanje stabala u prirodnim sastojinama bukve i hrasta;

- među štetnim biotskim čimbenicima najveće značenje za šume Srednje Bosne ima štetnik E. chrysorrhoea L.;

- broj ulovljenih jedinki zlatokraja na području Šumarije N. Travnik u 2014. godini je veći u odnosu na 2015. godinu za 6,35 puta;

- broj ulovljenih jedinki zlatokraja na području Šumarije Travnik u 2014. godini je manji u odnosu na 2015. godinu za 4,23 puta;

- broj ulovljenih jedinki zlatokraja na području Šumarije Kreševo u 2014. godini je manji u odnosu na 2015. godinu za 3,79 puta;

- korištenje feromona i feromonskih klopki u stadiju imaga utiče na smanjenje brojnosti ovog štetnika;

- uslijed gradacije štetnika, potrebno je postaviti veći broj feromonskih klopki.

\section{LITERATURA}

\section{REFERENCES}

- Abaei M. (2000): Pests of forest trees and shrubs of Iran. Agricultural Research, Education and Extension Organization, Tehran, Iran, $178 \mathrm{pp}$.

- Alford O.V. (1995): A colour atlas of pests of ornamental trees. Monson Publishing, London, UK, 414 pp.

- Arevalo-Durup, P. (1991): Le nidd'hiver d' Euproctis chrysorrhoea L. (Lepidoptera: Lymantriidae) comme estimateur de population en milieu forestier. Dissertation. Université Paul Sabatier, Toulouse, France.

- Candan, S., Suludere, Z. and Bayrakdar, F. (2007): Surface morphology of eggs of Euproctis chrysorrhoea (Linnaeus, 1758). Acta Zoologica (Stockholm) 88

- Chao, C.-L. (1978): Memoirs of Chinese economic entomology, vol. 12. Lepidoptera, Lymantriidae. Scientific Publ. Ctr., Peking, $121 \mathrm{pp}$

- Cleve K. (1972): “Der Goldafter (Euproctis chrysorrhoea L.) als Sanddornschädling”, Jahresbericht der Forschungsstelle für Insel- und Küstenschutz,Bd.XIII,1972.

- Elkinton, J. S., D. Parry, and G. H., Boettner (2006): Implicating an introduced generalist parasitoid in the invasive browntail moth's enigmatic demise. Ecology 87: 2664-2672.

- Elkinton, J. S., Preisser, E., Boettner, G., \& Parry, D. (2008): Factors influencing larval survival of the invasive browntail moth (Lepidoptera: Lymantriidae) in relict North American populations. Environmental entomology,37(6), 1429-1437.

- Eroğlu, M. (1992): Investigations on biology and damage of Euproctis chrysorrhoea (1.) (Lep., Lymantriidae). Proceedings of the Second Turkish National Congress of Entomolgoy, Adana, pp. 425-431. (in Turkish), Entomoloji Derneği Yayınları, No: 5.

- Frago, E., Selfa, J., Pujade-Villar, J., Guara, M. \& Bauce, E. (2009): Age and size thresholds for pupation and developmental polymorphism in the browntail moth, Euproctis chrysorrhoea (Lepidoptera: Lymantriidae), under conditions that either emulate diapause or prevent it. Journal of Insect Physiology, 55, 952-958.

- Frago, E., Guara, M., Pujade-Villar, J., Selfa, J. (2010): Winter feeding leads to a shifted phenology in the browntail moth Euproctis chrysorrhoea on the evergreen strawberry tree Arbutus unedo, Agricultural and Forest Entomology (2010), 12, 381-388.

- Grichanov, I. Ya. and Ovsyannikova, E. I. (2004): Pests: Euproctis chrysorrhoea Linnaeus - Browntail Moth. Interactive Agricultural Ecological Atlas of Russia and Neighboring Countries. Economic Plants and their Diseases, Pests and Weeds.

- Inoue, H. (1957): A revision of the Japanese Lymantriidae (11). Jap. Jour. Med. Sci. \& Biol. 10: 187-219.

- Khrimian, A., Lance, D. R., Schwarz, M., Leonhardt, B. A., and Mastro, V. C. (2008): Sex pheromone of browntail moth, Euproctis chrysorrhoea (L.): synthesis and field deployment. J. Agric. Food Chem. 56: 2452-2456.

- Lakatos, F., Tuba, K. (2011): The use of pheromones in the Hungarian forest management. Pheromones and other semio-chemicals IOBC/wprs Bulletin 72. pp. 15-21.

- Leonhardt, B.A., Mastro, V.C., Schwarz, M., Tang, J.D., Charlton, R.E., Pellegrini-Toole, A.,, J. D. Warthen Jr., J.D., Schwalbe, C.P., Cardé, R.T. (1991): Identification of sex pheromone of browntail moth, Euproctis chrysorrhoea (L.) (Lepidoptera: Lymantriidae), Journal of Chemical Ecology May 1991, Volume 17, Issue 5, pp 897-910 . 
- Lipa, J.J, J. Ziemnicka and J. Bartkowski (1980): [Collapse of the outbreak of brown tail moth due to epizotic of fungus Entomopthora aulicae (Reich.) in the south-western Poland]. Ochrona Roslin No. 1: 14-17 (in Polish).

- Lipa, J.J. (1996): Present status of noxious Lymantriidae in Europe and Poland. Integrated Management of Forest Lymantriidae, Proceedings of International Conference, March 27-29, 1996, Warsaw-Sckocin, Poland, IBL, Bitwy Warszawskiej 1920r, no 3, $274 \mathrm{pp}$.

- Marques, J.F. (2014): Genetic divergence and evidence for sympatric host-races in the highly polyphagous brown tail moth, Euproctis chrysorrhoea (Lepidoptera: Erebidae). Evolutionary Ecology, 28(5), pp.829 - 848.

- Mikloš, I. (1988): Rani šumski štetnici i njihovo značenje u zaštiti šuma. Šumarski list, br. 9-10, Zagreb.

- Nam, S.-H and C.-W. Kim (1981): A synonymic list of tussock moths (Orgyidae: Lep.) in Korean. Entomological Research Bulletin 8:73-100.

- Schaefer, P.W. (1974): Population ecology of the browntail moth, Euproctis chrysorrhoea (Lepidoptera: Lymantriidae). PhD thesis. University of Maine, Orono.

- Schaefer, P.W. (1986): Bibliography of the Browntail Moth, Euproctis chrysorrhoea (L.) (Lepidoptera: Lymantriidae) and its natural enemies. Agricultural Experiment Station, University of Delawaire Newark, Bulletin 464, 66 pp.

- Schaefer, P.W. (1989): Diversity in form, function, behavior, and ecology: an overview of the Lymantriidae (Lepidoptera) pf the world. Pp. 1-19. In Proceedings, Lymantriidae: A Comparison of Features of New and Old World Tussock Moths (W.E. Wallner \& K.A. McManus) (eds.). USDA,NEFS. Gen. Tech. Report NE-123, Broomal. 544 pp.

- Serafimovski, A., Kusevska, M., and Cepelak, J. (1976): Tahine (Dipt., Tachinidae) - paraziti žutotrbe (Euproctis chrysorrhoea L.) u Makedoniji, 1972-1974. Zaštita Bilja 27: 167- 179.

- Sliwa, E. (1993): [More Important Pests of Deciduous Trees] Swait, Warszawa, 79 pp. (in Polish).

- Stanivuković, Z. (2013): Najznačajniji defolijatori u šumama hrasta za vrijeme gradacije gubara (Lymantria dispar L.) u zapadnom dijelu Republike Srpske, Glasanik Šumarskog fakulteta Banjaluka, pp. 7-19.

- Sterling, P.H., P.M. Kelly, M.R. Speight and P.F. Entwistle (1988): The generation of secondary infection cycles following population of the Brown-tail moth, Euproctis chrysorrhoea L. (Lep., Lymantriidae). Journal of Applied Entomology 106, 302-311.

- Vasiljev, V.P., Livšic, I.Z. (1984): Вредители плодовых культур. М.: Колос.

\section{Summary}

Exploring the impact of pests E. chrysorrhoea L. was carried out in the area of Forest Office Travnik, Novi Travnik and Kreševo.

It was monitored population of E. chrysorrhoea L. by applying repressive measures which included the application of traps and pheromone. For the purposes of this study were used traps WitaTrap Delta PQ and pheromone Chrysowit. Monitoring populations of E. chrysorrhoea L. is analyzed in the 2014 and 2015 year, with the two measurements.

Based on the conducted field research led to the following conclusions:

- More adverse factors (abiotic and biotic nature) affects the decline of trees in natural stands of beech and oak;

- The most significant harmful biotic factor in forests of central Bosnia is pest E. chrysorrhoea L.;

- The number of caught individuals of Browntail Moth in Forest Office N. Travnik in 2014 year was higher than in the year 2015 for the 6,35 times; 